\section{Thermal Treatment of Chromium(III) Oxide with Carbonates Analyzed by Far-Infrared Spectroscopy}

\author{
Christian Vogel, ${ }^{a, *}$ Jan Stemann, ${ }^{a, b}$ \\ Karsten Holldack, ${ }^{c}$ Ryo Sekine, ${ }^{d}$ \\ Ewelina Lipiec, ${ }^{\mathrm{e}}$ Christian Adama \\ a BAM Federal Institute for Materials Research and \\ Testing, Division 4.4 Thermochemical Residues \\ Treatment and Resource Recovery, Unter den Eichen \\ 87, D-12205 Berlin, Germany \\ b Institute for Ecopreneurship, University of Applied \\ Sciences Northwestern Switzerland, Gründenstrasse \\ 40, 4132 Muttenz, Switzerland \\ c Helmholtz Zentrum Berlin, Institute Methods and \\ Instrumentation for Synchrotron Radiation Research, \\ 12489 Berlin, Germany \\ d Centre for Environmental Risk Assessment and \\ Remediation, University of South Australia, Mawson \\ Lakes, 5095 SA Adelaide, Australia \\ e The Henryk Niewodniczanski Institute of Nuclear \\ Physics, Polish Academy of Sciences E. \\ Radzikowskiego 152, 31-342 Kraków, Poland
}

\begin{abstract}
The chemical state of thermochemically treated chromium(III) oxide $\left(\mathrm{Cr}_{2} \mathrm{O}_{3}\right)$ with various carbonates was analyzed by far-infrared (farIR) spectroscopy (spectral region $700-25 \mathrm{~cm}^{-1}$ ). Non-toxic $\mathrm{Cr}_{2} \mathrm{O}_{3}$ was oxidized with potassium, sodium, and calcium carbonate, respectively, to toxic $\mathrm{Cr}(\mathrm{VI})$ and $\mathrm{Cr}(\mathrm{V})$ compounds during thermal treatment at $1000{ }^{\circ} \mathrm{C}$. In reverse, thermochemical treatment of $\mathrm{Cr}_{2} \mathrm{O}_{3}$ with magnesium carbonate lead to the formation of the $\mathrm{Cr}$ (III) compound $\mathrm{MgCr}_{2} \mathrm{O}_{4}$. Higher temperatures $\left(>1200{ }^{\circ} \mathrm{C}\right)$ or reducing atmospheric conditions prevent the formation of $\mathrm{Cr}(\mathrm{VI}) / \mathrm{Cr}(\mathrm{V})$ compounds, too. Additionally, it was found that polyethylene powder with a low particle size $(<70 \mu \mathrm{m})$ is favorable for the collection of good far-IR spectra of inorganic powders.
\end{abstract}

Index Headings: Far-infrared spectroscopy; Far-IR spectroscopy; Chromium; Carbonate; Chromate; Thermal treatment.

\section{INTRODUCTION}

Phosphorus $(\mathrm{P})$ is an essential element for all forms of life. For this reason, $\mathrm{P}$ in the form of phosphate is applied as fertilizer in the agricultural industry. Because $P$ is a limited mineral resource, new alternatives for the production of phosphate fertilizers must be found. An

Received 15 January 2015; accepted 5 March 2015.

* Author to whom correspondence should be sent. E-mail: cv.vogel@ yahoo.de.

DOI: $10.1366 / 15-07878$ important source of secondary phosphates is sewage sludge ash (SSA). ${ }^{1,2}$

Phosphates in SSA have a low plant availability. ${ }^{1}$ Furthermore, SSAs are polluted with heavy metals. ${ }^{1,2}$ To overcome these drawbacks, over the last several years, wet chemical and thermochemical processes were developed to separate pollutants from the SSA and to increase the plant availability of phosphorus. ${ }^{2-4}$ One important and promising process is the thermochemical treatment of SSA with sodium carbonate $\left(\mathrm{Na}_{2} \mathrm{CO}_{3}\right)$ at $850-1000{ }^{\circ} \mathrm{C}$ that increases the plant availability of the phosphate phases in the fertilizer due to the formation of $\mathrm{Na}-\mathrm{Ca}$ phosphates.

Sewage sludge ashes and SSA-based fertilizers contain approximately $80-200 \mathrm{mg} / \mathrm{kg}$ of total $\mathrm{Cr}$ with variable spread of oxidation states. Previously, we have reported that, under certain conditions, some chromium (III) in the SSA is oxidized to chromium(VI) during the thermochemical process. ${ }^{5}$ Chromium in the hexavalent state $(\mathrm{Cr}(\mathrm{VI}))$ is very toxic. In contrast, $\mathrm{Cr}$ in trivalent form $(\mathrm{Cr}(\mathrm{III}))$ is less mobile in the environment and therefore markedly less toxic. ${ }^{6}$ The German Fertilizer Ordinance ${ }^{7}$ mandates that the total $\mathrm{Cr}$ of fertilizers must be labeled above a content of $300 \mathrm{mg} / \mathrm{kg}$. Furthermore, the $\mathrm{Cr}(\mathrm{VI})$ mass fraction is limited to $2 \mathrm{mg} / \mathrm{kg}$ irrespective of the overall amount of $\mathrm{Cr}$ present in the fertilizer.

Thus, in order to meet the strict $\mathrm{Cr}(\mathrm{VI})$ limit in the German Fertilizer Ordinance, we analyzed the behavior of $\mathrm{Cr}$ during thermochemical treatment of pure chromium(III) oxide $\left(\mathrm{Cr}_{2} \mathrm{O}_{3}\right)$ with various carbonates under varied oxygen atmospheres by far-infrared (far-IR) spectroscopy. Far-IR spectroscopy is an appropriate method because most of the infrared absorption bands of metal oxides occur in the spectral region $700-25 \mathrm{~cm}^{-1}$, as shown for several examples of heavy metal oxides in Fig. 1. Thus, changes of the chemical state of $\mathrm{Cr}$ during thermal treatment can be studied by far-IR spectroscopy to understand the state of $\mathrm{Cr}$ in the SSA fertilizer. An overview about the oxidation state of different chromium compounds is shown in Table I.

\section{MATERIALS AND INSTRUMENTATION}

Thermogravimetry-differential thermal analysis (TGDTA) experiments were carried out on Netzsch STA 449 F3 Jupiter (Selb, Germany). Samples of 20-30 mg were heated at a rate of $10{ }^{\circ} \mathrm{C} / \mathrm{min}$ from $30{ }^{\circ} \mathrm{C}$ to $800 / 1000 /$ $1200{ }^{\circ} \mathrm{C}$ after which, the temperature was kept constant for $30 \mathrm{~min}$. The gas flow (air, nitrogen-air mixture, or argon $+2 \%$ hydrogen) was $50 \mathrm{~mL} / \mathrm{min}$. The thermal experiments were done with chromium(III) oxide $\left(\mathrm{Cr}_{2} \mathrm{O}_{3}\right.$, p.a., Merck, Darmstadt, Germany), calcium carbonate $\left(\mathrm{CaCO}_{3}\right.$, p.a., Sigma-Aldrich, Steinheim, Germany), magnesium carbonate $\left(\mathrm{MgCO}_{3}\right.$, p.a., Merck, Darmstadt, Germany), $\mathrm{Na}_{2} \mathrm{CO}_{3}(>99 \%$, Carl Roth $\mathrm{GmbH}$, Karlsruhe 


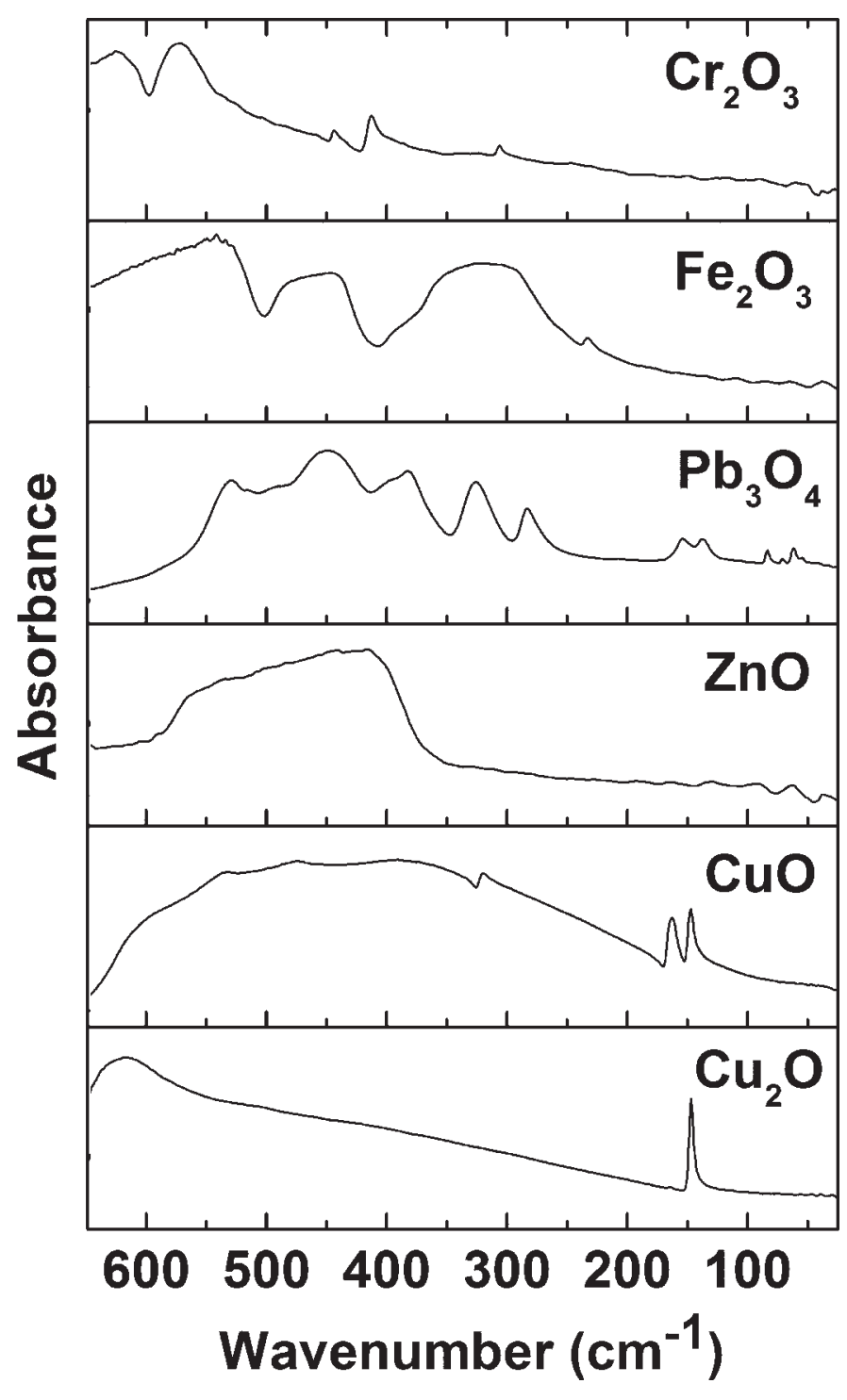

FIG. 1. Far-IR spectra of various metal oxides.

Germany), and potassium carbonate $\left(\mathrm{K}_{2} \mathrm{CO}_{3}\right.$, J.T. Baker, Deventer, The Netherlands).

Calcium chromate $\left(\mathrm{CaCrO}_{4}\right)$ and chromium sulfide $\left(\mathrm{Cr}_{2} \mathrm{~S}_{3}\right.$; both $\mathrm{ABCR}$, Karlsruhe, Germany), sodium chromate $\left(\mathrm{Na}_{2} \mathrm{CrO}_{4}, 98+\%\right.$, ACROS Organics, Geel, Belgium), potassium chromate $\left(\mathrm{K}_{2} \mathrm{CrO}_{4}\right.$, p.A., AppliChem, Karlsruhe, Germany), iron(III) oxide $\left(\mathrm{Fe}_{2} \mathrm{O}_{3}\right)$ and zinc oxide (ZnO; Sigma-Aldrich, Steinheim, Germany), lead oxide $\left(\mathrm{Pb}_{3} \mathrm{O}_{4}\right.$, Fisher Scientific, Leicestershire, UK), copper(II) oxide (CuO, Carl Roth $\mathrm{GmbH}$, Karlsruhe, Germany), and copper(I) oxide $\left(\mathrm{Cu}_{2} \mathrm{O}, 99 \%\right.$, Alfa-Aesar, Karlsruhe,

TABLE I. Oxidation states of various chromium compounds.

\begin{tabular}{ll}
$\begin{array}{l}\text { Oxidation } \\
\text { state }\end{array}$ & \multicolumn{1}{c}{ Compounds } \\
\hline $\mathrm{Cr}(\mathrm{III})$ & $\mathrm{Cr}_{2} \mathrm{O}_{3}, \mathrm{Cr}(\mathrm{OH})_{3}, \mathrm{CrCl}_{3}, \mathrm{CaCr}_{2} \mathrm{O}_{4}, \mathrm{MgCr}_{2} \mathrm{O}_{4}, \mathrm{FeCr}_{2} \mathrm{O}_{4}, \mathrm{Cr}_{2} \mathrm{~S}_{3}$ \\
$\mathrm{Cr}(\mathrm{IV}) /(\mathrm{V})$ & $\mathrm{Ca}_{5} \mathrm{Cr}_{3} \mathrm{O}_{12}$ \\
$\mathrm{Cr}(\mathrm{V})$ & $\mathrm{Ca}_{3} \mathrm{Cr}_{2} \mathrm{O}_{8}$ \\
$\mathrm{Cr}(\mathrm{VI})$ & $\mathrm{CaCrO}_{4}, \mathrm{MgCrO}_{4}, \mathrm{Na}_{2} \mathrm{CrO}_{4}, \mathrm{~K}_{2} \mathrm{CrO}_{4}$ \\
\hline
\end{tabular}

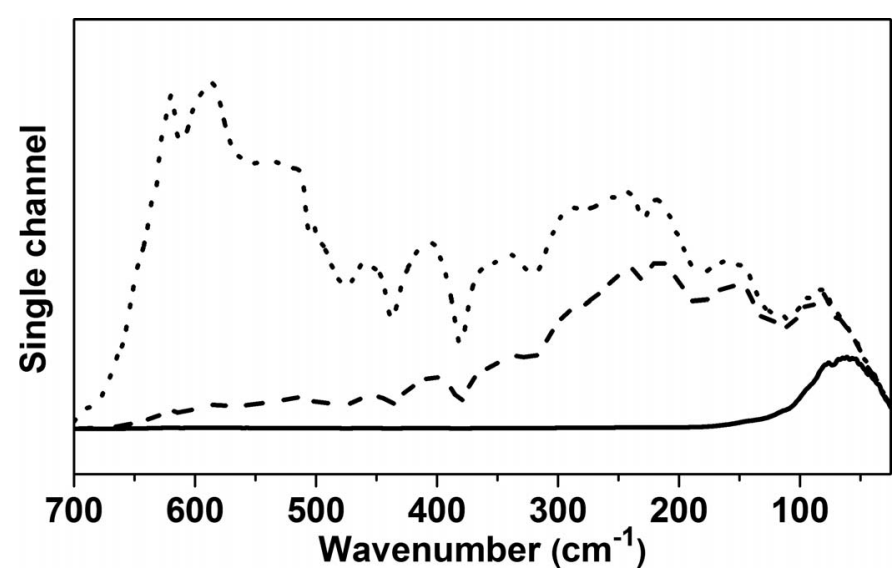

FIG. 2. Single channel spectra of various PE powders (Micro Powders (average particle size $4.5 \mu \mathrm{m}$, dotted line), Vestolen (average particle size $60 \mu \mathrm{m}$, dashed line), ABCR (average particle size $>150 \mu \mathrm{m}$, solid line).

Germany) were used for the spectroscopic experiments (standards reference spectra). Chromium hydroxide $\left(\mathrm{Cr}(\mathrm{OH})_{3}\right)$ was precipitated from an aqueous solution of chromium(III) chloride $\left(\mathrm{CrCl}_{3}\right.$, p.a., Sigma-Aldrich, Australia) with ammonia. Calcium chromite $\left(\mathrm{CaCr}_{2} \mathrm{O}_{4}\right)$, magnesium chromite $\left(\mathrm{MgCr}_{2} \mathrm{O}_{4}\right)$, and chromite $\left(\mathrm{FeCr}_{2} \mathrm{O}_{4}\right)$ were prepared from $1.00 \mathrm{~g} \mathrm{Cr}_{2} \mathrm{O}_{3}$ (p.a., Merck, Darmstadt, Germany) with $0.66 \mathrm{~g} \mathrm{CaCO}_{3}$ (p.a., Sigma-Aldrich, Steinheim, Germany), $0.66 \mathrm{~g} \mathrm{MgCO}_{3}$ (p.a., Merck, Darmstadt, Germany), and $0.51 \mathrm{~g}$ iron(II,III) oxide $\left(\mathrm{Fe}_{3} \mathrm{O}_{4}, 95 \%, \mathrm{ABCR}\right.$, Karlsruhe, Germany) at 1250, 1000, and $1500{ }^{\circ} \mathrm{C}$, respectively, in platinum crucibles by thermal treatment $(6-16 \mathrm{~h}$ ) in a muffle furnace (Nabertherm LH 15/14, Lillenthal, Germany). ${ }^{8} \mathrm{Ca}_{3} \mathrm{Cr}_{2} \mathrm{O}_{8}$ and $\mathrm{Ca}_{5} \mathrm{Cr}_{3} \mathrm{O}_{12}$ were prepared from $\mathrm{Cr}_{2} \mathrm{O}_{3}$ (p.a., Merck, Darmstadt, Germany) and $\mathrm{CaCO}_{3}$ (p.a., Sigma-Aldrich, Steinheim, Germany) at 1000 and $1200{ }^{\circ} \mathrm{C}$, respectively, after Arcon et al. ${ }^{9}$ in platinum crucibles by thermal treatment in a muffle furnace.

Far-IR spectroscopic measurements of the thermochemically treated samples were carried out at the Terahertz Beamline at Helmholtz-Zentrum Berlin (Bruker IFS 125, far-IR DTGS-detector with black PEwindow, multilayer beam splitter (Bruker T222)). Reference substances were measured at the Terahertz Beamline at Helmholtz-Zentrum Berlin and Far-Infrared and High-Resolution FT-IR Beamline at the Australian Synchrotron (Bruker IFS 125, He-cooled Si-bolometer, multilayer beam splitter). Spectra were collected with a spectral resolution of $2 \mathrm{~cm}^{-1}$ (100 scans were co-added per spectrum) in transmission. For comparison of the data, some samples were measured on both instruments. For the analysis of the far-IR transparency of polyethylene (PE) powders, the following high-density PE powders were used: Micro Powders Inc. MPP620XXF (average particle size $4.5 \mu \mathrm{m}$; Tarrytown, NY), Vestolen A6016 (average particle size $60 \mu \mathrm{m}$; Hüls, Germany) and ABCR PE UHMW (average particle size $>150 \mu \mathrm{m}$; Karlsruhe, Germany). For the collection of farIR spectra of the metal oxides, $3 \mathrm{mg}$ of sample were ground with a pestle and mortar and afterwards mixed with $47 \mathrm{mg}$ PE powder (Vestolen). The sample/PE 


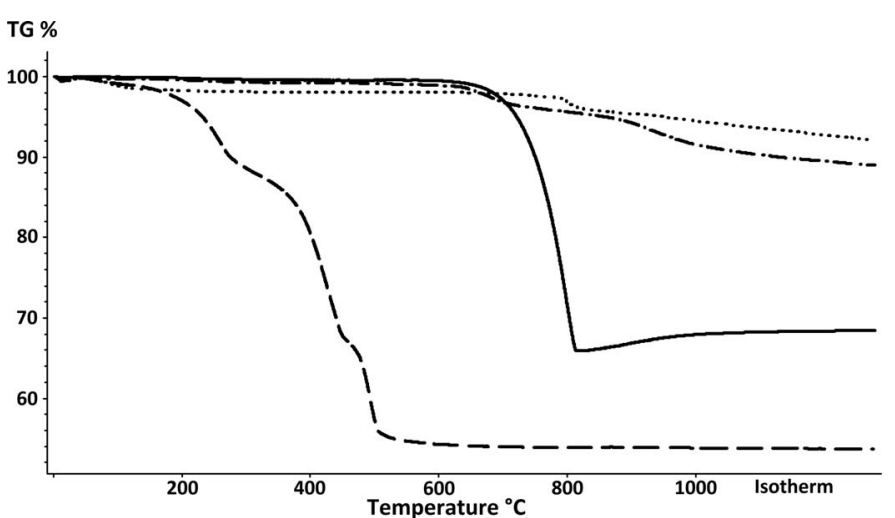

FIG. 3. Thermogravimetry (TG) curves of thermochemical treatment of $\mathrm{Cr}_{2} \mathrm{O}_{3}$ with $\mathrm{MgCO}_{3}$ (dashed line), $\mathrm{CaCO}_{3}$ (solid line), $\mathrm{Na}_{2} \mathrm{CO}_{3}$ (dasheddotted line), and $\mathrm{K}_{2} \mathrm{CO}_{3}$ (dotted line; atmosphere: air; heating rate: $10 \mathrm{~K} / \mathrm{min}$; isotherm segment: $30 \mathrm{~min}$ ).

mixture was pressed without heating in a pellet press (13 $\mathrm{mm}$ diameter) for $1 \mathrm{~min}$ with a pressure of 5 tons. The pellet thickness after pressing was approximately $0.5 \mathrm{~mm}$.
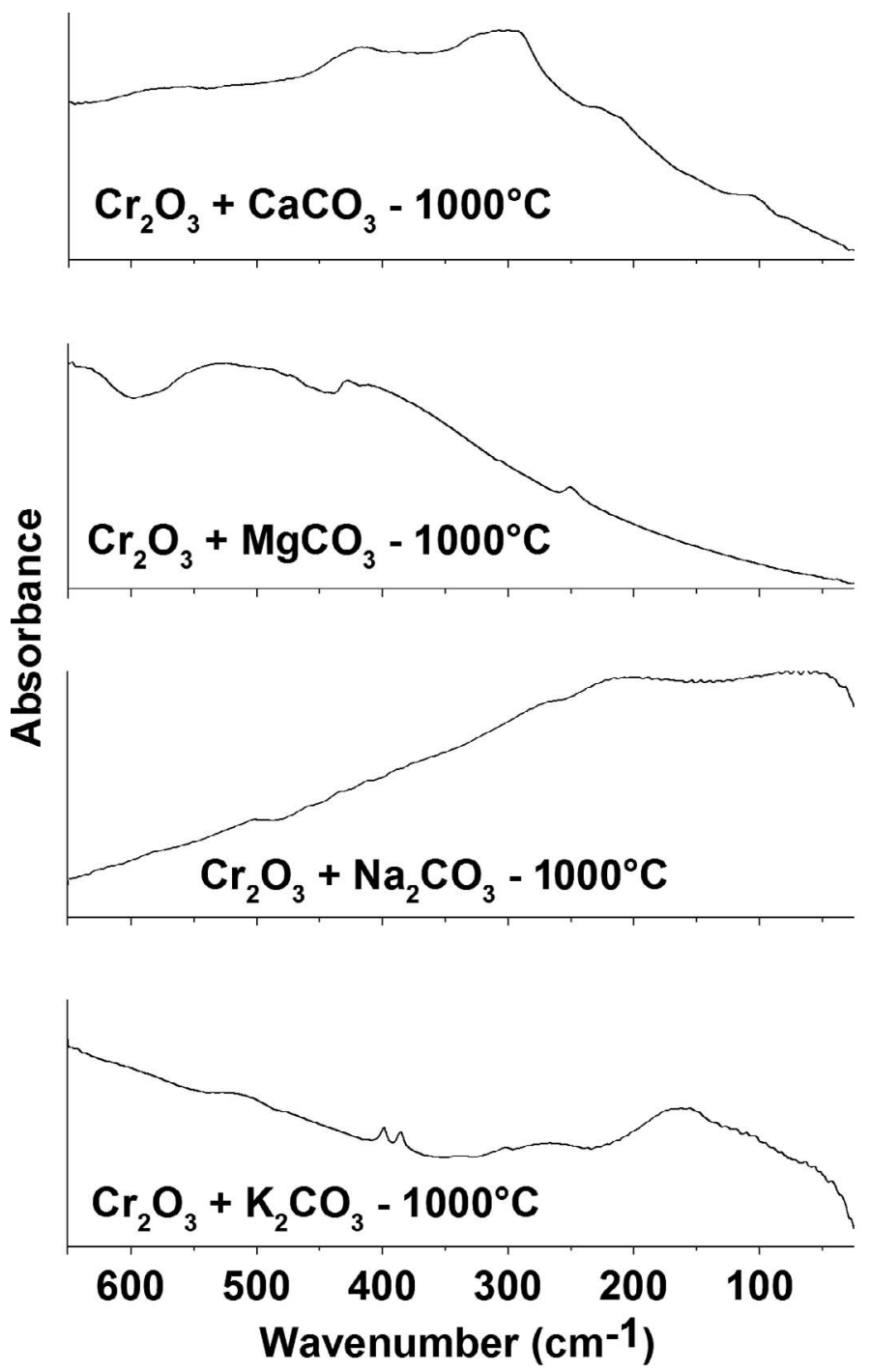

\section{RESULTS AND DISCUSSION}

Far-IR transparency of the used PE powder is a critical issue for the collection of far-IR absorption spectra with a high spectral quality. Figure 2 shows the single channel spectra of three different PE powders. The highest infrared radiation transparence in the $700-25 \mathrm{~cm}^{-1}$ region was found for the PE powder with the lowest average particle size (Micro powders, $4.5 \mu \mathrm{m}$ ). With an increasing average particle size of the PE powder, a decreasing infrared radiation transparency was detected, with the high energy cutoff wavenumber almost reciprocal to the grain size of the PE powder. ${ }^{10}$ Thus, higher grain sizes of the PE powder result in stronger scattering of the infrared radiation whereby more $\mathrm{IR}$ radiation is lost.

Figure 3 shows the TG curves of thermal treatment of $\mathrm{Cr}_{2} \mathrm{O}_{3}$ with $\mathrm{CaCO}_{3}, \mathrm{MgCO}_{3}, \mathrm{Na}_{2} \mathrm{CO}_{3}$, and $\mathrm{K}_{2} \mathrm{CO}_{3}$, respectively. The reaction of $\mathrm{Cr}_{2} \mathrm{O}_{3}$ with $\mathrm{MgCO}_{3}$ starts already at low temperatures of approximately $300{ }^{\circ} \mathrm{C}$. In contrast, the reactions of $\mathrm{Cr}_{2} \mathrm{O}_{3}$ with $\mathrm{CaCO}_{3}, \mathrm{Na}_{2} \mathrm{CO}_{3}$, and $\mathrm{K}_{2} \mathrm{CO}_{3}$ start at approximately $750{ }^{\circ} \mathrm{C}$. Figure 4 shows the far-IR spectra of the reaction products of these thermal
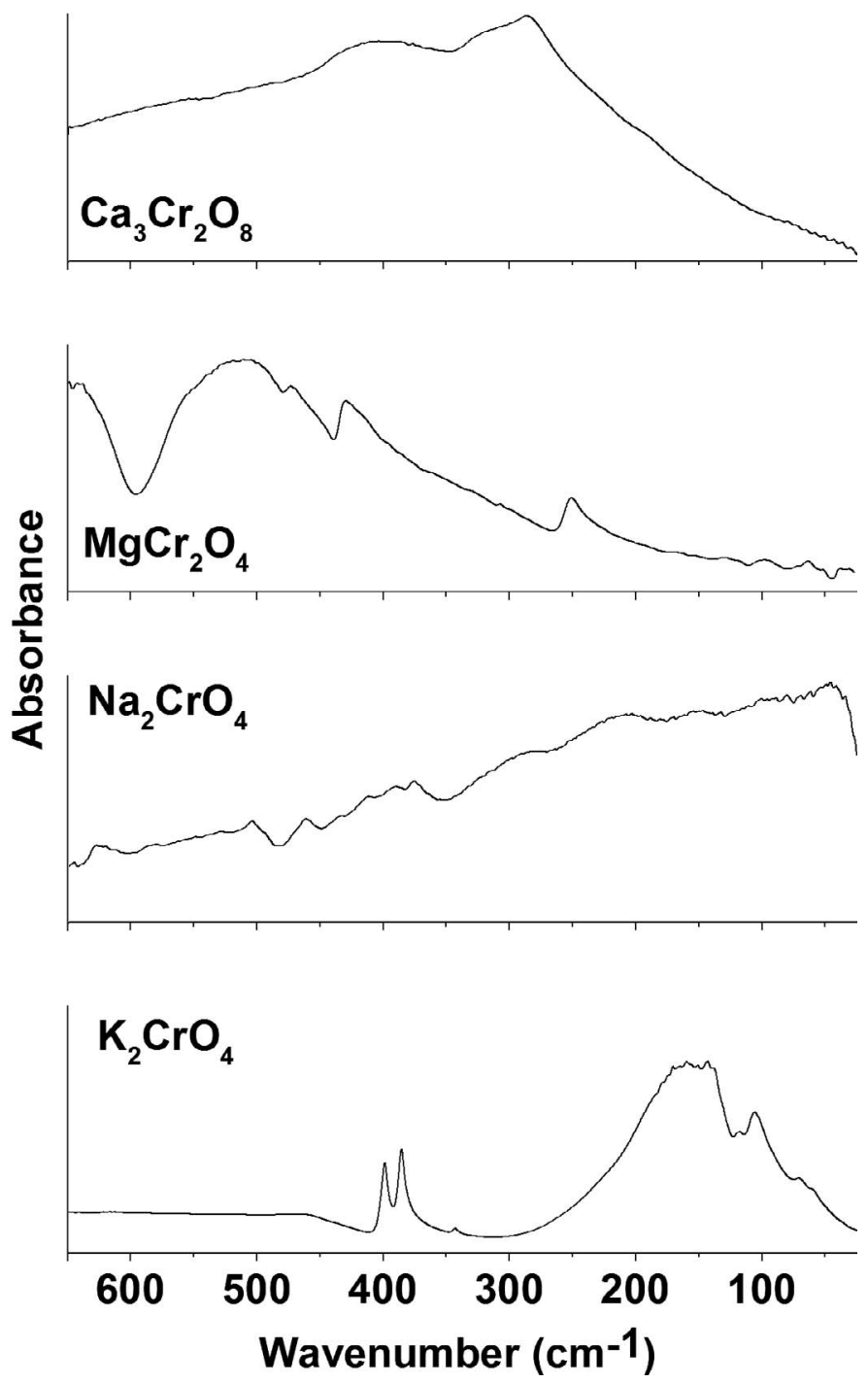

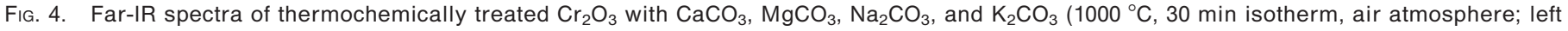
column) and corresponding reference substances (right column). 


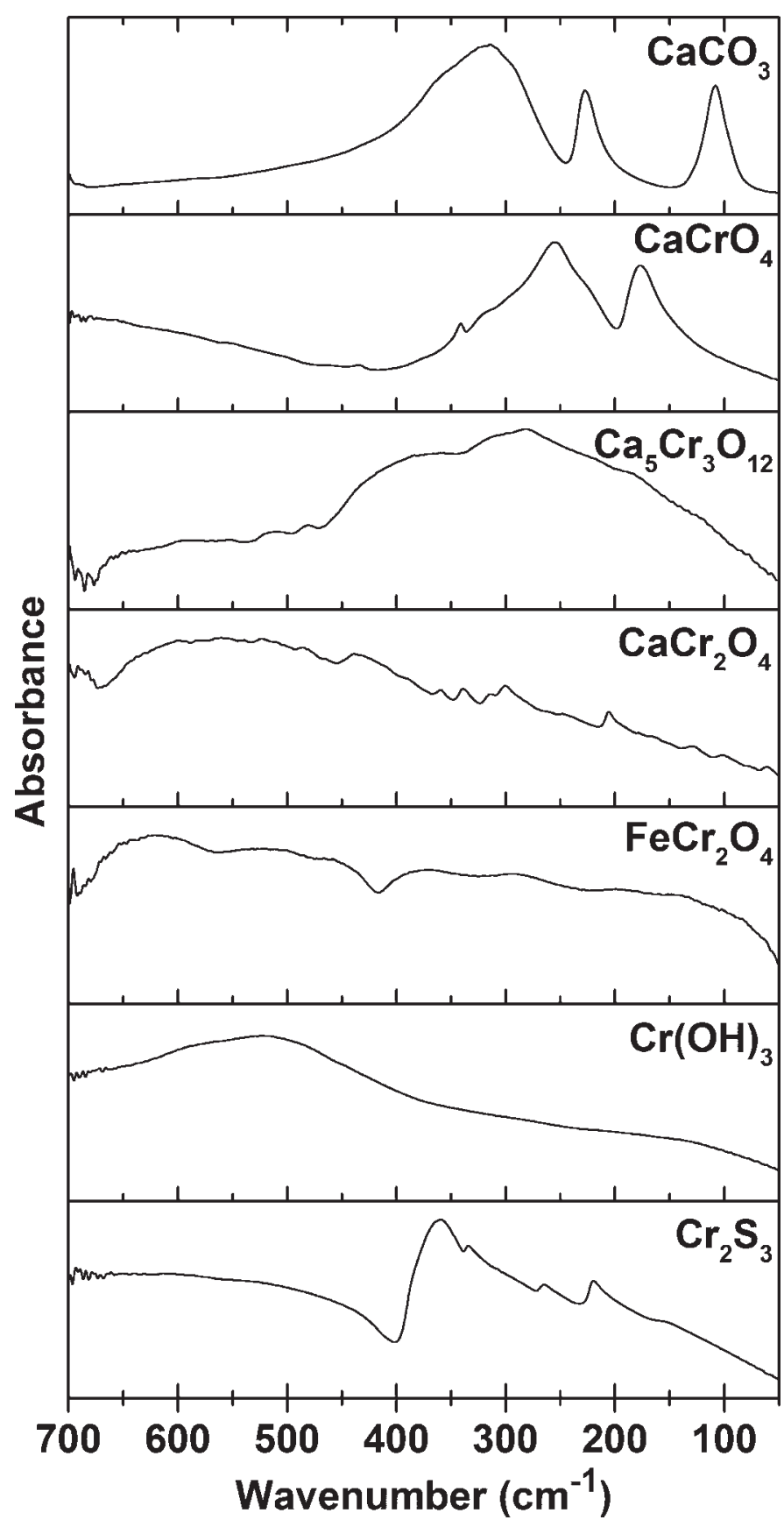

FIG. 5. Far-IR spectra of calcium carbonate and various chromium compounds.

treatments at $1000{ }^{\circ} \mathrm{C}$ (left side). Thermal treatment of $\mathrm{Cr}_{2} \mathrm{O}_{3}$ with $\mathrm{Na}_{2} \mathrm{CO}_{3}$ and $\mathrm{K}_{2} \mathrm{CO}_{3}$ developed the $\mathrm{Cr}(\mathrm{VI})$ compounds $\mathrm{Na}_{2} \mathrm{CrO}_{4}$ and $\mathrm{K}_{2} \mathrm{CrO}_{4}$, respectively (see corresponding spectra of reference substances on the right side). $\mathrm{K}_{2} \mathrm{CrO}_{4}$ has characteristic sharp absorption bands at 399, 385, and $155 \mathrm{~cm}^{-1}$. In reverse, in the spectrum of $\mathrm{Na}_{2} \mathrm{CrO}_{4}$, only a broad band at lower wavenumbers is detectable. During the treatment with $\mathrm{MgCO}_{3}$, the $\mathrm{Cr}(\mathrm{III})$ compound $\mathrm{MgCr}_{2} \mathrm{O}_{4}$ is formed. It was previously determined that magnesium chromate $\left(\mathrm{MgCrO}_{4}\right)$ is thermally stable only up to approximately $700{ }^{\circ} \mathrm{C}^{8}$ At higher temperatures, it decomposes to the trivalent chromite $\mathrm{MgCr}_{2} \mathrm{O}_{4}$. However, $\mathrm{Na}_{2} \mathrm{CrO}_{4}$ and $\mathrm{K}_{2} \mathrm{CrO}_{4}$ are stable until temperatures $>1000{ }^{\circ} \mathrm{C}{ }^{8}$

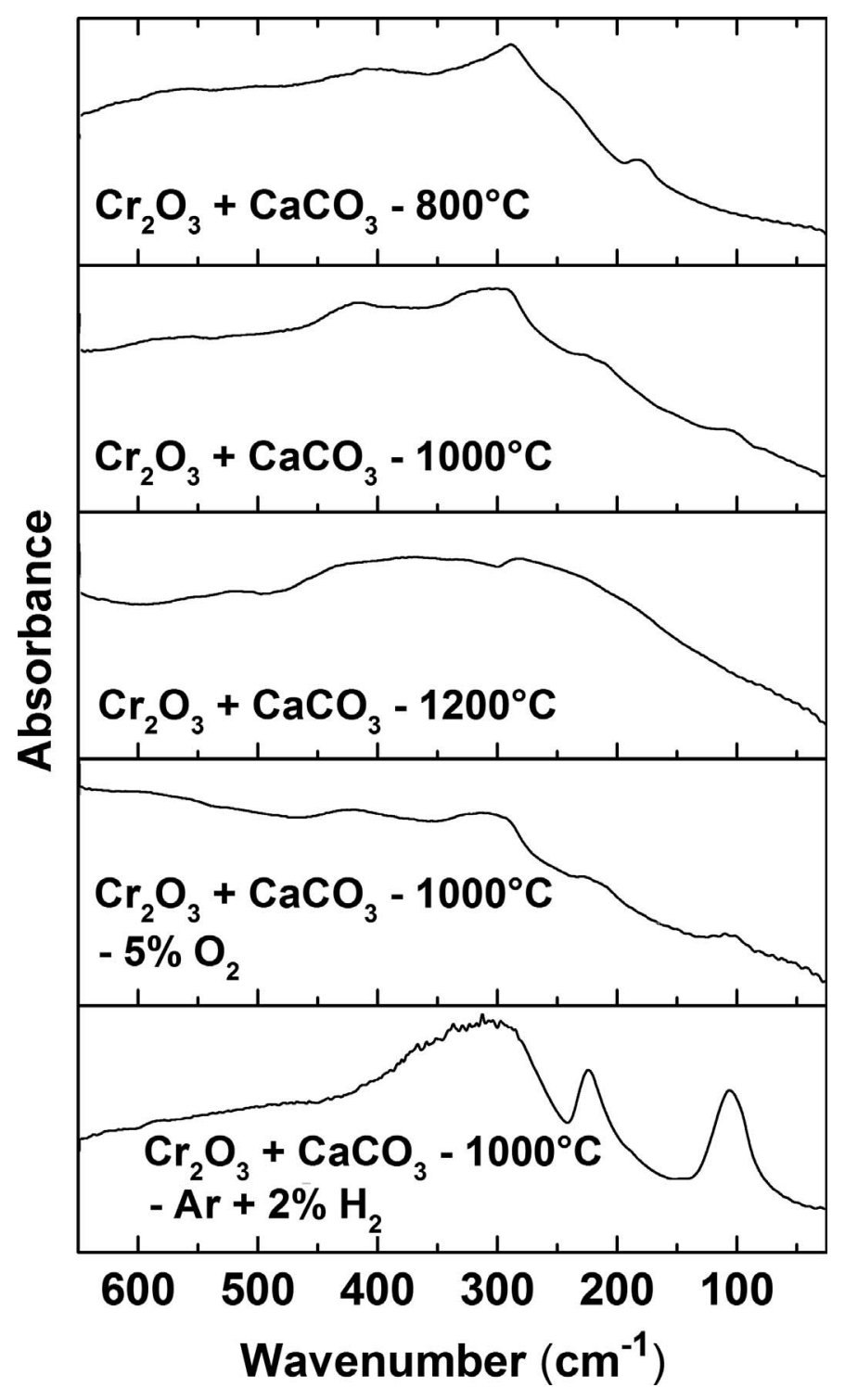

FIG. 6. Far-IR spectra of thermochemically treated $\mathrm{Cr}_{2} \mathrm{O}_{3}$ with $\mathrm{CaCO}_{3}$ at 800,1000 , and $1200^{\circ} \mathrm{C} \mathrm{(30} \mathrm{min} \mathrm{isotherm,} \mathrm{air} \mathrm{atmosphere;} \mathrm{first} \mathrm{three} \mathrm{from}$ top to bottom) and thermochemically treated $\mathrm{Cr}_{2} \mathrm{O}_{3}$ with $\mathrm{CaCO}_{3}$ at 1000 ${ }^{\circ} \mathrm{C}$ under 5 vol\% oxygen and reducing conditions $\left(2 \% \mathrm{H}_{2}\right.$ in $\left.\mathrm{Ar}\right)$.

The major product of the thermal treatment of $\mathrm{Cr}_{2} \mathrm{O}_{3}$ with $\mathrm{CaCO}_{3}$ at $1000{ }^{\circ} \mathrm{C}$ is the $\mathrm{Cr}(\mathrm{V})$ compound $\mathrm{Ca}_{3} \mathrm{Cr}_{2} \mathrm{O}_{8}$ $\left(=\mathrm{Ca}_{3}\left(\mathrm{CrO}_{4}\right)_{2}\right)$. In the spectrum, some unreacted $\mathrm{CaCO}_{3}$ is also detectable at its bands at 315,228 , and $110 \mathrm{~cm}^{-1}$ (see also Fig. 5, top). Figure 6 also shows the far-IR spectra of the products from the thermal treatment of $\mathrm{Cr}_{2} \mathrm{O}_{3}$ with $\mathrm{CaCO}_{3}$ at 800 and $1200{ }^{\circ} \mathrm{C}$, respectively. Similar to the $1000{ }^{\circ} \mathrm{C}$ treatment, the product of the treatment at $800{ }^{\circ} \mathrm{C}$ shows $\mathrm{Ca}_{3} \mathrm{Cr}_{2} \mathrm{O}_{8}$ as a major mineral phase formed. Furthermore, some bands of the $\mathrm{Cr}(\mathrm{VI})$ compound $\mathrm{CaCrO}_{4}$ at 256 and $178 \mathrm{~cm}^{-1}$ are detectable. For comparison, far-IR spectra of other chromium reference compounds are shown in Fig. 6. Holder and Schwarz ${ }^{11}$ showed that $\mathrm{Ca}_{3} \mathrm{Cr}_{2} \mathrm{O}_{8}$ is developed by thermal treatment of $\mathrm{CaCrO}_{4}$ with calcium oxide $(\mathrm{CaO})$. Thus, primarily $\mathrm{CaCrO}_{4}$ will be formed, which reacts during the thermal treatment with developing $\mathrm{CaO}$, from the combustion of $\mathrm{CaCO}_{3}$, to the $\mathrm{Cr}(\mathrm{V})$ compound 
$\mathrm{Ca}_{3} \mathrm{Cr}_{2} \mathrm{O}_{8}$. Equations 1 and 2 show the reactions of $\mathrm{Cr}_{2} \mathrm{O}_{3}$ with small and large amounts of $\mathrm{CaCO}_{3}$, respectively.

$$
\begin{gathered}
\mathrm{Cr}_{2} \mathrm{O}_{3}+2 \mathrm{CaCO}_{3}+\frac{3}{2} \mathrm{O}_{2} \rightarrow 2 \mathrm{CaCrO}_{4}+2 \mathrm{CO}_{2} \\
\mathrm{Cr}_{2} \mathrm{O}_{3}+3 \mathrm{CaCO}_{3}+\mathrm{O}_{2} \rightarrow \mathrm{Ca}_{3} \mathrm{Cr}_{2} \mathrm{O}_{8}+3 \mathrm{CO}_{2}
\end{gathered}
$$

The thermal treatment at $1200{ }^{\circ} \mathrm{C}$ results in a predominant formation of the $\mathrm{Cr}(\mathrm{V}) / \mathrm{Cr}(\mathrm{IV})$ compound $\mathrm{Ca}_{5} \mathrm{Cr}_{3} \mathrm{O}_{12}\left(=\mathrm{Ca}_{5}\left(\mathrm{CrO}_{4}\right)_{3}\right)$ and some $\mathrm{Ca}_{3} \mathrm{Cr}_{2} \mathrm{O}_{8}$. Previously, it was mentioned that, at temperatures $>1000{ }^{\circ} \mathrm{C}$, a decomposition of $\mathrm{Cr}(\mathrm{VI})$ to $\mathrm{Cr}(\mathrm{III})$ takes place. ${ }^{8,12} \mathrm{Howev}$ er, the presented results show that the thermally initiated reduction of $\mathrm{Cr}(\mathrm{VI})$ to $\mathrm{Cr}(\mathrm{III})$ does not take place in one step, but runs through the chemical states $\mathrm{Cr}(\mathrm{V})$ and Cr(IV).

With a reduced oxygen concentration in the atmosphere (5 vol\% instead of $20 \mathrm{vol} \%$ ), bands at 420 and $288 \mathrm{~cm}^{-1}$ indicate that $\mathrm{Ca}_{3} \mathrm{Cr}_{2} \mathrm{O}_{8}$ was again formed during thermochemical treatment of $\mathrm{Cr}_{2} \mathrm{O}_{3}$ with $\mathrm{CaCO}_{3}$ at $1000{ }^{\circ} \mathrm{C}$ (see Fig. 6). In this spectrum, again, some $\mathrm{CaCO}_{3}$ is detectable at its bands at 315,228 , and $110 \mathrm{~cm}^{-1}$. Only reducing atmospheric conditions (a mixture of $2 \%$ hydrogen in argon was used) prevent an oxidation of $\mathrm{Cr}(\mathrm{III})$ to toxic $\mathrm{Cr}(\mathrm{VI}) / \mathrm{Cr}(\mathrm{V})$ compounds (Fig. 6, bottom). No reaction between $\mathrm{Cr}_{2} \mathrm{O}_{3}$ and $\mathrm{CaCO}_{3}$ was detectable under reducing conditions. The spectrum shows a mixture of pure $\mathrm{Cr}_{2} \mathrm{O}_{3}$ (weak absorption bands at 626 and $\left.572 \mathrm{~cm}^{-1}\right)$ and pure $\mathrm{CaCO}_{3}(315,228$, and $110 \mathrm{~cm}^{-1}$ ) bands. In the literature, ${ }^{8}$ it is also mentioned that $\mathrm{Cr}_{2} \mathrm{O}_{3}$ is not reduced by hydrogen even at high temperatures which can be confirmed by our results.

\section{CONCLUSIONS}

In this paper, we demonstrated the ability of far-IR spectroscopy for the determination of the chemical state of inorganic chromium compounds. Thermochemical treatment of $\mathrm{Cr}_{2} \mathrm{O}_{3}$ with $\mathrm{CaCO}_{3}, \mathrm{Na}_{2} \mathrm{CO}_{3}$, and $\mathrm{K}_{2} \mathrm{CO}_{3}$, respectively, at $1000{ }^{\circ} \mathrm{C}$ developed toxic $\mathrm{Cr}(\mathrm{VI})$ and $\mathrm{Cr}(\mathrm{V})$ compounds. Higher temperatures $\left(>1200^{\circ} \mathrm{C}\right)$ or reducing atmospheric conditions are required to prevent the formation of these toxic compounds. In contrast, thermochemical treatment of $\mathrm{Cr}_{2} \mathrm{O}_{3}$ with $\mathrm{MgCO}_{3}$ led solely to the formation of the $\mathrm{Cr}(\mathrm{III})$ compound $\mathrm{MgCr}_{2} \mathrm{O}_{4}$ because $\mathrm{MgCrO}_{4}$ is only stable up to approximately $700{ }^{\circ} \mathrm{C}$. Furthermore, it was demonstrated that PE powder with a low particle size $(<70 \mu \mathrm{m})$ is necessary for the collection of far-IR spectra with a high quality.

\section{ACKNOWLEDGMENTS}

This research was undertaken on the Far-Infrared and HighResolution FT-IR Beamline at the Australian Synchrotron, Victoria, Australia, and Terahertz Beamline at Helmholtz-Zentrum Berlin, Germany. We thank these institutions for the allocation of synchrotron radiation beamtime. Christian Vogel thanks the German Research Foundation for financial support (VO 1794/1-1 and VO 1794/2-1). We also gratefully acknowledge Anka Kohl (BAM, Division 1.4) for help with the pellet preparation and Dr. Marion Gemeinert (BAM, Division 5.5) for the analysis of the particle size.

1. O. Krüger, A. Grabner, C. Adam. "Complete Survey of German Sewage Sludge Ash”. Environ. Sci. Technol. 2014. 48(20): 1181111818.

2. C. Adam, B. Peplinski, M. Michaelis, G. Kley, F.-G. Simon. "Thermochemical Treatment of Sewage Sludge Ashes for Phosphorus Recovery". Waste Manage. 2009. 29(3): 1122-1128.

3. C. Vogel, C. Adam. "Heavy Metal Removal from Sewage Sludge Ash by Thermochemical Treatment with Gaseous Hydrochloric Acid". Environ. Sci. Technol. 2011. 45(17): 7445-7450.

4. S. Donatello, C.R. Cheeseman. "Recycling and Recovery Routes for Incinerated Sewage Sludge Ash (ISSA): A Review". Waste Manage. 2013. 33(11): 2328-2340.

5. C. Vogel, C. Adam, P. Kappen, T. Schiller, E. Lipiec, D. McNaughton. "Chemical State of Chromium in Sewage Sludge Ash Based Phosphorus-Fertilizers". Chemosphere. 2014. 103: 250255.

6. A.K. Shanker, C. Cervantes, H. Loza-Tavera, S. Avudainayagam "Chromium Toxicity in Plants". Environ. Int. 2005. 31(5): 739-753.

7. German Fertilizers Ordinance. Ordinance on the Circulation of Fertilizers, Soil Nutrients, Soil Substrates and Plant Protection Substances. Bundesgesetzblatt. 2008. Pt. I (60): 2524-2581.

8. L. Gmelin. Handbuch der anorganischen Chemie, Chrom [B]. Weinheim (Bergstrasse): Verlag Chemie Germany, 1962. Pp. 42-43, 55-56, 466, 468, 518, 784, 807.

9. I. Arcon, B. Mirtic, A. Kodre. "Determination of Valence States of Chromium in Calcium Chromates by Using X-Ray Absorption NearEdge Structure (XANES) Spectroscopy". J. Am. Ceram. Soc. 1998. 81(1): 222-224.

10. P. Born, K. Holldack, M. Sperl. "Particle Characterization Using THz Spectroscopy”. Granular Matter. 2014. arXiv:1407.6592.

11. R. Holder, H. Schwarz. "Zur Kenntnis der Erdalkaliechromate(V)". Zeitschrift für anorgische Chemie. 1963. 326: 11-24.

12. F. Solymosi, I. Nagy. "On the Reactions Occurring in the CaOCr2O3-O2 System". Zeitschrift für anorgische Chemie. 1970. 378(2): 217-224. 